\title{
O CONSUMIDOR JOVEM PERCEBE INOVAÇÕES? A HEURÍSTICA NAS ESCOLHAS DE BAIXO ENVOLVIMENTO
}

\section{THE YOUNG CONSUMER PERCEIVES INNOVATIONS? THE HEURISTIC IN LOW INVOLVEMENT CHOICES}

\section{Cláudio Heleno Pinto da Silva}

Mestrando em Administração na Universidade Federal de Uberlândia - UFU

Uberlândia, MS, Brasil

E-mail: claudiohps@gmail.com

\section{Clarice Mara Sousa-e-Silva}

Mestranda em Administração na Universidade Federal de Uberlândia - UFU

Uberlândia, MS, Brasil

E-mail: claricemara@hotmail.com

André Francisco Alcântara Fagundes

Professor do Mestrado em Administração na Universidade Federal de Uberlândia - UFU

Uberlândia, MS, Brasil

E-mail: andrefagundes@fagen.ufu.br

\section{RESUMO}

Esta pesquisa objetiva verificar a influência da heurística e das crenças de mercado nas escolhas consumeristas de baixo envolvimento que apresentam inovações. Foram entrevistados jovens consumidores, buscando-se compreender o processo de escolha de sucos prontos. Por meio da análise de conteúdo, percebeu-se como principais atributos no processo de escolha e identificação das inovações: sabor, marca, embalagem e preço. Também se verificou que os jovens pesquisados consideram crenças de mercado como "compre a melhor e mais conhecida marca", bem como tendem a utilizar a heurística para desconsiderar as informações disponíveis, decidindo de maneira rápida e pouco reflexiva. Com o aumento de envolvimento com a decisão, os respondentes diminuíram a influência da heurística e analisaram as inovações de maneira mais racional.

Palavras-chave: Heurística. Comportamento do Consumidor. Inovação. Sucos Prontos.

Data de submissão: 25 de fevereiro de 2015.

\section{ABSTRACT}

The purpose of this exploratory research is to verify the influence of the heuristic and market beliefs in consumer choices of low involvement presenting innovations. It was interviewed 31 young people, trying to understand the process of choice of juices ready. Through content analysis, it was identified the main attributes in the selection process and identification of innovations: flavor, brand, packaging and price. It was found that young people surveyed consider market beliefs as "buy the best and bestknown brand", as well as tend to use heuristics to reduce the information available, deciding quickly little reflective. With increasing involvement with the decision, respondents decreased the influence of heuristic analyzed innovations in a more rational way.

Keywords: Heuristic. Consumer Behavior. Innovation. Ready Juices.

Data de aprovação: 25 de abril de 2018. 


\section{INTRODUÇÃO}

Em um cenário pautado por mudanças constantes nas preferências dos consumidores e nas ações dos concorrentes (DE PAULA, 2008), a inovação poder ser fator diferencial para as organizações adquirirem vantagem competitiva. Inovar é desenvolver e implantar novidades, tais como novos processos e ideias que impactem na produtividade da empresa, em seus conceitos originais, novos produtos, ou até mesmo em novos arranjos (VAN DE VEN et al., 1999; COSTA et al, 2011).

A inovação em produtos pode ser uma prática necessária para que esses obtenham sucesso. Entretanto, com a extensa quantidade de produtos disponíveis, questiona-se se os consumidores realmente conseguem perceber inovações lançadas pelas organizações. Estudos ligados à racionalidade limitada, como aponta Lindenberg (1992), têm evidenciado que não. Ao contrário do que afirmam os estudos sobre a plena racionalidade humana, Simon (1957, apud LUPPE; ANGELO, 2010, p.102) propôs que seres humanos são limitados "em sua habilidade de processar informações e tomar decisões, portanto os indivíduos valem-se, no processo decisório, de heurísticas ou 'regras práticas' para simplificar o ambiente complexo, rico em informações, em que formam suas percepções". A partir desta proposição, Tversky e Kahneman (1971; 1973; 1974) realizaram pesquisas na área e mostraram que os indivíduos se utilizam da heurística para auxiliar e simplificar o processo de decisão, o qual pode ser realizado com base em um número menor de informações.

No Brasil, a abordagem da heurística tem sido utilizada, por exemplo, nas ciências contábeis, buscando compreender o processo decisório de contadores (MACEDO et al 2012); na administração pública, para mostrar a influência da mídia na percepção que os cidadãos têm da realidade (CIARELLI; ÁVILA, 2009); na formação estratégia empresarial (GOMES et al., 2012); e nas práticas orçamentárias (LIMA FILHO et al., 2010).

No campo do comportamento do consumidor, Luppe e Angelo (2010) investigaram a influência da heurística de ancoragem no processo decisório dos consumidores em relação à percepção e à estimação dos preços de produtos e serviços. Santos et al. (2010) pesquisaram a influência da heurística na escolha de uma instituição de ensino superior. Já Bezerra e Leone (2013) mostraram que o valor das estimativas individuais em relação aos produtos de cesta básica pode ser influenciado por valores âncoras (heurísticas).

Ainda com relação ao comportamento do consumidor, o uso da heurística em processos de decisões simplificadas pode gerar crenças de mercado para a realização de escolhas (DUNCAN; OLSHAVSKY, 1982; JOHN et al,1986; DUNCAN, 1990). Para Sherman e Corty (1984), os consumidores usam as crenças de mercado porque elas proveem foco e encorajam o indivíduo a selecionar e prestar atenção em aspectos específicos, podendo reduzir a complexidade da decisão e permitir ao comprador fazer julgamentos mais rápidos e com menor esforço cognitivo.

Utilizando-se a abordagem da racionalidade limitada, com foco na heurística e nas crenças de mercado, o objetivo geral desta pesquisa é verificar a influência desses dois aspectos nas escolhas consumeristas de baixo envolvimento que apresentam inovações. Para isto, a pesquisa tem como objetivos específicos: identificar atributos inovadores em um bem de consumo de baixo envolvimento, e; identificar e analisar quais heurísticas e crenças de mercado podem influenciar na percepção de atributos.

Para alcançar os objetivos propostos, a presente pesquisa utilizou como objeto de estudo sucos prontos para beber, um produto considerado de baixo envolvimento. O mercado brasileiro de bebidas não 
alcoólicas, que abrange a produção de sucos prontos, está em expansão. O crescimento da produção de sucos e néctares é mais acelerado que de outros tipos de bebidas e estima-se que o crescimento do setor seja de $9 \%$ ao ano e superior ao de refrigerantes, por exemplo, que é de $2 \%$ (ABREU, 2013).

A próxima etapa do artigo é a revisão de literatura, que aborda os pressupostos da teoria de envolvimento, heurística, crenças de mercado e inovação. Na sequência, os aspectos metodológicos serão detalhados. Subsequentemente, os dados serão analisados e uma discussão acerca do resultado da pesquisa será feita, buscando atender aos objetivos propostos.

\section{A HEURÍSTICA NAS DECISÕES DE CONSUMO E A INOVAÇÃO}

Muitas decisões são tomadas diariamente. Desde as mais complexas, como a decisão de submeterse a uma cirurgia de alto risco, até algo mais simples, como comprar um suco pronto para beber. Porém, o processamento de informações de uma pessoa ocorre em um sistema com capacidade limitada, levando-a a realizar tarefas dentro das suas limitações cognitivas (PAYNE, 1976).

Para ajudar na tarefa de escolha, indivíduos tendem a realizar predições acerca de suas possíveis decisões, levando em consideração as experiências vividas (NELSON, 1970). Babutsidze (2012) sugere que em uma situação de escolha, naturalmente as pessoas buscam por informações oriundas das suas experiências anteriores ou de fontes externas, para que possa chegar à melhor decisão. Por meio destas fontes, uma pessoa pode construir ferramentas e mapas para facilitar a análise dos fatos, chamados de heurísticas, e assim escolher com esforço reduzido e menos investimentos.

No caso da escolha de um produto em uma gôndola de supermercado, apesar das informações estarem disponíveis ao consumidor, elas podem estar em quantidade e/ou forma que o levem a realizar um grande esforço de compreensão para, posteriormente, realizar a tomada de decisão (MARCH; FELDMANN, 1991 apud BRESSAN, 2004). Surge então uma lacuna que é preenchida por atalhos para facilitar a tomada de decisões, as heurísticas, que diminuem a complexidade das tarefas. Recursos cognitivos úteis, mas que também podem levar a erros sistemáticos, pois os indivíduos não conseguem processar todos dados disponíveis, retendo-se exclusivamente à análise de alguns (TVERSKY; KAHNEMAN, 1974).

Heurística é a utilização de regras baseadas em padrões já existentes com o fim de resolver um problema ou situação (MARCH, 1994). Russo e Schoemaker (1990), conceituam heurística como um processo formado por atalhos mentais, que dão suporte a uma tomada de decisão, reduzindo o esforço de análise dos dados e contribuindo para um resultado considerado "correto". Como os seres humanos têm limitada capacidade de processamento das informações, as heurísticas são, de modo geral, atalhos mentais que minimizam os esforços e aceleram o processo de tomada de decisões (TVERSKY; KAHNEMAN, 1974; PAYNE, 1976).

Em um competitivo mercado com grande disponibilidade de informações elevado número de ofertas, o consumidor tende a utilizar recursos nem sempre tão precisos para facilitar a tomada de decisões de compra. A simplificação das decisões dos consumidores pode acarretar em dificuldades no reconhecimento de atributos inovadores e/ou importantes para ele. Assim, é possível considerar que a utilização da heurística pode trazer prejuízos para o indivíduo em suas decisões. No entanto, apesar dos potenciais prejuízos, não 
se pode negar a sua influência no mundo contemporâneo, pois se exige dos indivíduos decisões ágeis a todo momento (TONETTO et al., 2006).

Babutsidze (2012) procura entender "como os consumidores fazem suas escolhas?". Para o autor, as decisões podem ser influenciadas por fatores internos (como a personalidade) e externos (como o meio social). Dessa forma, o autor estabelece diferenças entre os tipos de escolhas vivenciadas pelos consumidores e propõe que o fenômeno da realização da decisão seja compreendido por meio de dois fatores: (a) a experiência do consumidor com a escolha em questão (pouca/muita experiência); e (b) a dificuldade da escolha (fácil/difícil). Em uma combinação destes dois aspectos, o autor sugere, por exemplo, que em condições de muita experiência para realizar uma escolha fácil, consumidores experts podem utilizar os recursos da heurística - atalhos mentais - para tomar sua decisão, já estão acostumados a realizar este tipo de seleção com frequência. Já quando o consumidor é inexperiente e a escolha é difícil (por exemplo, na aquisição de um bem durável de alto valor), eles buscam mais informações para processar sua escolha, dando menos ênfase à heurística. No entanto, à medida que a complexidade da decisão aumenta, é possível que o consumidor inexperiente lance mão da heurística para decidir, pois pode não conseguir lidar com tantas informações sem a experiência necessária para interpretá-las e usá-las em uma decisão racional. Ainda, quando um consumidor está diante de uma escolha fácil e de baixo envolvimento, provavelmente irá usar a heurística para decidir sem grande esforço (BABUTSIDZE, 2012).

Estabelecer as diferenças entre os diversos contextos de decisão é importante para que o estudo do comportamento do consumidor aprofunde-se no fenômeno das escolhas consumeristas, pois diversos tipos de compras são realizadas no contexto de baixo envolvimento. Neste caso, é frequente o uso da heurística para facilitar as escolhas, como por exemplo, o consumo de bens não duráveis. Babutsidze (2012) aponta que a maioria das escolhas referentes a esta categoria são realizadas no ponto de venda, sujeitas a influência da heurística. Leong (1993) compartilha a mesma proposição, sugerindo que as decisões de baixo envolvimento realizadas dentro de uma loja não são processos extensos, mas são julgamentos simples, baseados na percepção da possível performance do produto.

As influências internas e externas a que um consumidor está sujeito são de diversas naturezas. Em relação a essas influências, Dijksterhuis et al. (2005) pesquisaram a importância do meio ambiente nas decisões de compra. Propõem que as escolhas realizadas em supermercados são fortemente influenciadas pelo meio no qual o indivíduo está incluído e algumas destas influências ambientais estão catalogadas empiricamente. Russo e Leclerc (1994) verificaram a influência da posição de produtos na gôndola na escolha dos consumidores. Dentre seus achados, verificaram que a escolha realizada era um processo imperfeito, baseada em preferências parcialmente conscientes e realizada sob influência de ações promovidas no ponto de venda.

Na mesma direção, Chandon et al. (2009) pesquisaram a influência da posição de um produto na gôndola, relacionando-a a marca e ao tempo em que cada consumidor fixava o olhar no item. A pesquisa evidenciou, por exemplo, que os consumidores frequentes de determinada marca são influenciados pela posição do produto na gôndola, buscando-o com olhar e decidindo-se de maneira mais rápida.

A marca de um produto pode ser, portanto, uma importante influência ambiental que ocorre com frequência nos supermercados, sendo um relevante elemento para a criação de uma heurística facilitadora de decisões na mente dos consumidores. Maheswaran et al (1992) pesquisaram como a marca transforma- 
se em matéria-prima para formar uma heurística muito usada pelos consumidores: em situações de baixo envolvimento, nas quais os consumidores estão cientes da pouca relevância que sua escolha terá, tendem a optar pela marca mais conhecida.

Por outro lado, o estudo demonstrou que o consumidor tende a abandonar decisões heurísticas e decidir-se de maneira mais consciente à medida que tomam conhecimento de informações sobre atributos do produto, atenuando assim o impacto que uma marca forte impõe no mercado.

O uso constante da heurística leva os consumidores a buscarem mecanismos que facilitem as decisões, conhecidas também como 'crenças de mercado'. Para Duncan e Olshavsky (1982), essas crenças podem expressar associações generalizadas entre classes de objetos (compradores, produtos e vendedores) e entre atributos de produto (preço, qualidade, etc.), agindo diretamente no comportamento de compra. Para Sherman e Corty (1984), consumidores usam as crenças porque elas proveem foco e os encorajam a selecionar e prestar atenção em aspectos específicos. Ao reduzir a complexidade da decisão, elas permitem ao comprador fazer julgamentos mais rápidos com menos esforço cognitivo do que uma análise sem esses recursos. O Quadro 1 apresenta algumas dessas crenças identificadas na literatura, que podem ajudar na compreensão de comportamentos de compra de baixo envolvimento.

\section{Quadro 1 - Crenças de mercado}

\begin{tabular}{|c|c|}
\hline Crenças de Mercado & Autor \\
\hline Produtos com muito empenho de propaganda são mais caros. & \multirow{3}{*}{ Duncan e Olshavsky (1982); Duncan (1990) } \\
\hline $\begin{array}{l}\text { Organizações que fazem mais propagandas vendem os melhores } \\
\text { produtos. }\end{array}$ & \\
\hline O consumidor é mau avaliador quando se trata de compras técnicas. & \\
\hline $\begin{array}{l}\text { Em mercados com informações imperfeitas, consumidores usarão o } \\
\text { preço como perspectiva de escolha, em relação ao nível de qualidade } \\
\text { de diferentes alternativas pouco familiarizadas. }\end{array}$ & $\begin{array}{l}\text { Sciotvsky (1945) apud Duncan (1990); } \\
\text { Wolinsky (1983) }\end{array}$ \\
\hline $\begin{array}{l}\text { Consumidores geralmente relacionam preço com qualidade do } \\
\text { produto. }\end{array}$ & $\begin{array}{l}\text { Enis e Stafford (1969); Gardner (1970); } \\
\text { Monroe (1976); Olson (1977) }\end{array}$ \\
\hline $\begin{array}{l}\text { Inferências da qualidade do produto estão relacionadas ao (1) } \\
\text { investimento em propaganda; (2) market share; (3) garantia do } \\
\text { produto; (4) imagem da marca; e (5) tempo no mercado. }\end{array}$ & $\begin{array}{l}\text { (1) Salop (1978); (2) FTC Publication (1979); } \\
\text { (3) e (4) Allison e Uhl (1964); Gardner } \\
\text { (1971); Jacoby, Szybillo e Busato-Schach } \\
\text { (1977); (5) Beales et al. (1981) }\end{array}$ \\
\hline $\begin{array}{l}\text { Consumidores que acreditam que preço seja uma referência de } \\
\text { qualidade tendem a escolher produtos mais caros. }\end{array}$ & John et al. (1986) \\
\hline $\begin{array}{l}\text { Consumidores usam a heurística da lembrança da marca "compre a } \\
\text { melhor e mais conhecida marca", e tendem a selecionar algumas } \\
\text { poucas marcas de referência para se decidirem em situação de } \\
\text { escolhas simples. }\end{array}$ & Hoyer e Brown (1990) apud Leong (1993) \\
\hline
\end{tabular}

Fonte: Elaborado pelos autores. 
Diante da perspectiva do uso de heurísticas e crenças de mercado para realizar escolhas de baixo envolvimento, questiona-se se os consumidores de fato percebem inovações propostas pelas organizações em seus produtos. Uma forma de alcançar e manter vantagem competitiva diante da dinamicidade do mercado está na busca pela inovação e implementação de novos produtos, serviços, processos, dentre outros fatores. Rogers e Shoemaker (1971) afirmam que a inovação pode ser uma prática, uma ideia ou, simplesmente, um novo material utilizado em um processo. Dentre os diversos conceitos de inovação na literatura, esta será a abordagem utilizada nesta pesquisa.

Rogers (1983) defende que inovação se refere ao novo, considerando que há um espaço temporal entre o desenvolvimento e implementação da ideia, chamado de "processo de inovação". Ele divide esse processo em 5 etapas: (i) conhecimento; (ii) persuasão; (iii) decisão; (iv) implementação; e (vi) confirmação, sendo essa última etapa a busca por reforçar se a ideia trouxe ou não resultados. Portanto, perceber uma inovação em um produto, sob a ótica de Rogers (1983), faz parte do processo de sua implementação.

Como o objeto de estudo desta pesquisa é um alimento - sucos prontos - optou-se por analisar mais especificamente as inovações para esse tipo de produto. Hansen (2005), ao pesquisar a percepção que os consumidores tinham em relação aos alimentos, verificou que os indivíduos têm mais expectativas em questões ligadas à aparência do que ao preço. Além disso, sua pesquisa aponta para o fato de que o consumo de alimentos não é apenas a obtenção de nutrientes, mas sim um fenômeno psicológico (cognitivo e afetivo). $\mathrm{O}$ autor sugere que o processo de percepção de qualidade envolve variáveis pessoais (experiências, por exemplo) e situacionais (propósito de compra, por exemplo).

Guo e Yin (2014) pesquisaram como a atitude dos consumidores em relação a atributos de inovação dos produtos influencia os seus comportamentos de compra e utilizaram um suco integral para suas análises. Os autores identificaram que os atributos de inovação podem ter influência positiva sobre o comportamento de compra dos consumidores e apresentaram quatro fatores presentes nas inovações de produto:

a) Aumento da qualidade do produto - aspectos ligados à melhoria contínua da qualidade da produção, relacionado aos sentidos, como olfato e paladar, e também à percepção de preço e conveniência. No mercado de comidas e bebidas, Ortega-Rivas (2010) apud Guo e Yin (2014) citam como características sabor, odor, irritações químicas, textura do alimento, aparência, conveniência, branding, processamento do alimento e tradições alimentares.

b) Melhoria de propriedades úteis - esse aspecto se relaciona a questões como aprimoramento dos atributos nutricionais, impacto em uma vida saudável e aumento de qualidade de vida; aspectos como composição nutricional que propicie uma boa saúde e propriedades funcionais estão incluídos nesta dimensão.

c) Mudanças no design (embalagem) - estudos de Rahman e McCarthy (1999) apud Guo e Yin (2014) associam o design da embalagem à qualidade do produto e à melhoria de propriedades úteis. No mercado de comidas e bebidas, as embalagens não têm apenas função de armazenar, mas também precisam preservar as características dos produtos, o que aumenta a importância da embalagem diante da percepção do consumidor (RICHERS, 2000).

d) Redução de impactos ambientais - considera questões como embalagem reciclável, produtos orgânicos sem agrotóxicos e preservação florestal. De maneira geral, o material da embalagem se transformou em 
importante padrão para que os consumidores definissem o que são produtos de qualidade (BEHARRELL, 1991; BONILLA, 2010 apud GUO; YIN, 2014).

Considerando os aspectos levantados por Guo e Yin (2014) foi desenvolvido um instrumento de coleta de dados com o objetivo de identificar as características de inovação que influenciam o comportamento de compra de consumidores de sucos prontos. Esses aspectos serão analisados sob a perspectiva da heurística, seguindo os passos metodológicos apresentados a seguir.

\section{ASPECTOS METODOLÓGICOS}

A presente pesquisa consiste em uma investigação empírica do tipo exploratória, pois se aprofunda na análise de determinada realidade (TRIVIÑOS, 1987). Malhotra (2001) considera que pesquisa exploratória pode ser utilizada quando se busca o entendimento da natureza geral de um problema. Para o alcance dos objetivos, selecionou-se 31 estudantes da Universidade Federal de Uberlândia (UFU) para participar do estudo, por meio de uma entrevista semiestruturada. Para Malhotra (2006), esse instrumento trata da união entre perguntas não-estruturadas (abertas), que têm o intuito de possibilitar que o entrevistado expresse livremente suas opiniões, juntamente com questões estruturadas, ou respostas no formato conhecido como de múltipla escolha.

Quatro marcas de suco pronto foram utilizadas para a realização da coleta de dados: Del Valle, Sufresh, Do Bem e Natural One, sendo que as duas últimas são de suco integral. O sabor escolhido foi laranja, devido à sua representatividade no mercado de bebidas em geral, pois é a bebida mais consumida no mundo, com 35\% de participação entre os sucos (CITRUS BR, 2014).

A escolha das marcas que participaram do estudo obedeceu à combinação de dois critérios. Primeiramente, foram selecionadas duas marcas, Del Valle e Sufresh, que de acordo com a ABRAS (2014), são líderes de mercado em todas as regiões do Brasil. Em visita aos principais supermercados varejistas de Uberlândia-MG (Carrefour, Extra, Wal-Mart e Bretas) e varejos de bairro (De Ville e Empório Prátiko), ambas foram encontradas. O outro critério, utilizado para escolher as marcas Do Bem e Natural One, foi a presença de atributos diferenciados dos líderes de mercado - (i) Do Bem: primeira marca a lançar suco Detox e suco integral (100\% fruta e sem açúcar) em embalagem Tetrapak, design minimalista da embalagem com foco em adultos jovens, utiliza linguagem informal nas suas embalagens, apresentando informações adicionais e dados sobre a produção do suco; e (ii) Natural One: oferece sucos com blending de sabores (kiwi e laranja, por exemplo), possui embalagem transparente, apresenta suco integral (100\% fruta e sem açúcar).

Após pesquisa nos principais varejistas da cidade, o preço médio dos sucos Del Valle e Sufresh foi de $R \$ 5,02$ (litro) e dos sucos Natural One e Do Bem foi de $R \$ 8,42$. Pressupõe-se que, dentre os aspectos que explicam o preço médio maior dos sucos Natural One e Do Bem (67\% mais caro que os sucos líderes de mercado), esteja a adoção de características inovadoras. Assim, optou-se por categorizar os produtos em dois grupos: os sucos Del Valle e Sufresh como Grupo I (líderes de mercado) e os sucos Do Bem e Natural One Grupo II (produtos mais inovadores e mais caros).

A amostra obtida foi selecionada por conveniência e limitada a respondentes que tinham, na data da pesquisa, entre 18 e 25 anos e consumiam suco de laranja. A escolha por esse público-alvo deve-se ao fato 
de que o suco Do Bem apresenta um conjunto de características inovadoras declaradamente em suas embalagens voltadas para o público jovem.

Os respondentes apresentaram o seguinte perfil: $65 \%$ do sexo masculino, possuem entre 18 e 25 anos, solteiros, cursando nível superior e a renda familiar da maioria dos respondentes (58\%) é de 4 a 10 salários mínimos. $80 \%$ (25 respondentes) consomem suco de laranja pronto para beber de uma a quatro vezes por mês e declararam aceitar pagar, em média, até o valor de $R \$ 4,68 /$ litro de suco pronto, o que corresponde a $20 \%$ a mais que a média nacional - $R \$ 3,71 /$ litro (ABRAS, 2014).

A coleta de dados foi realizada no dia 12 de novembro de 2014, em um restaurante e lanchonete localizado dentro do Campus Santa Mônica da UFU em Uberlândia-MG. Após a seleção dos respondentes, eles eram conduzidos a uma mesa onde os quatro tipos de sucos processados de laranja foram dispostos, com o preço sugerido em evidência, sendo que a disposição dos itens era alterada a cada entrevista - Quadro 2 .

Quadro 2 - Sucos de laranja utilizados na degustação

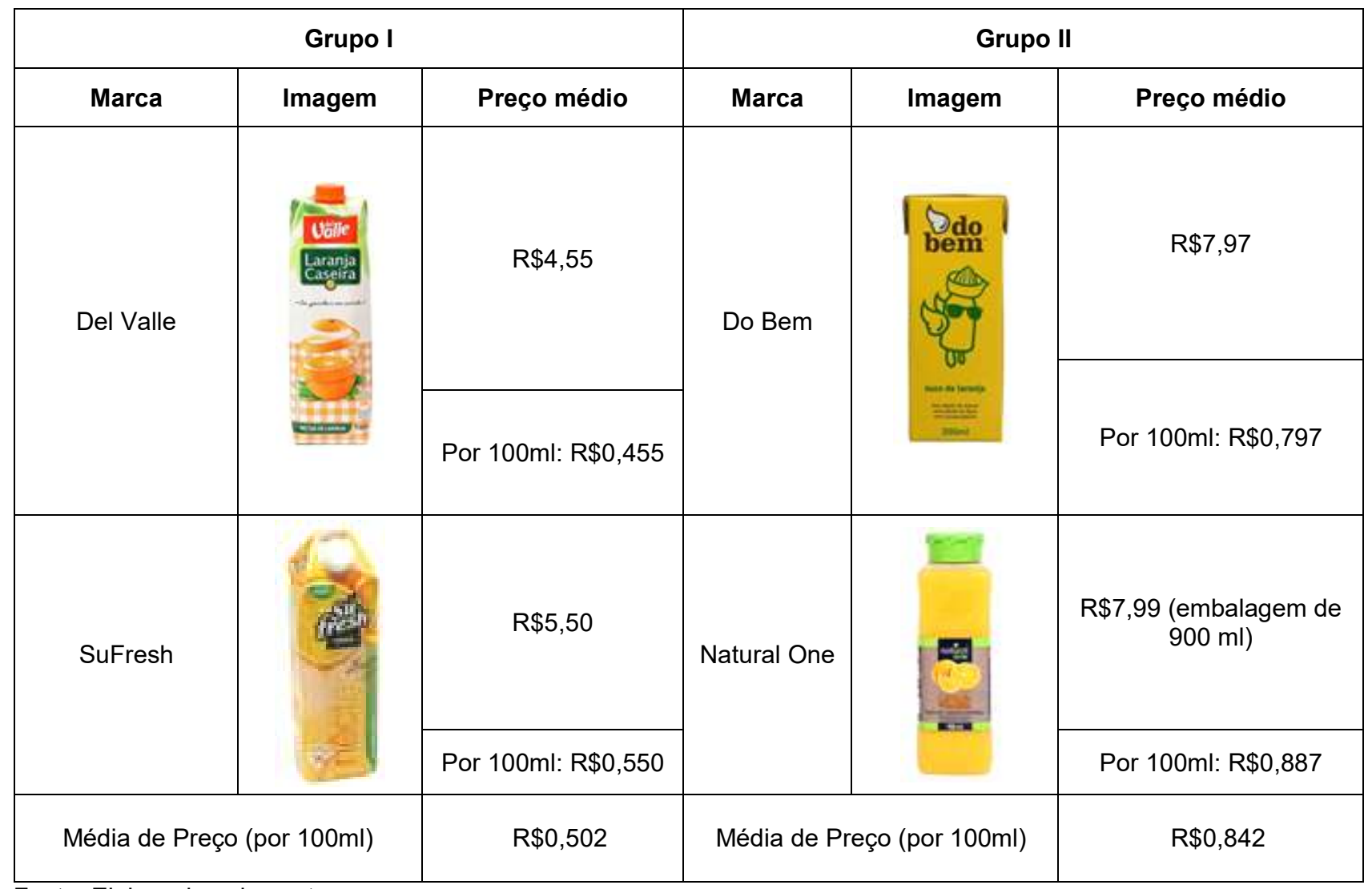

Fonte: Elaborado pelos autores.

$\mathrm{Na}$ primeira etapa, o respondente era questionado abertamente sobre o que considerava inovador em sucos prontos, bem como do que considerava importante no momento de escolher um suco pronto na gôndola do supermercado. Na etapa seguinte, o participante era apresentado diretamente aos sucos e questionava-se qual deles ele escolheria, se estivesse realizando uma compra de supermercado, e por quê. Ressalte-se que a pergunta era aberta, e os respondentes poderiam indicar quaisquer atributos livremente, sem determinação de quantidade mínima ou máxima. 
Após a escolha e justificativa, o respondente era convidado a experimentar todos os sucos. Posteriormente, o entrevistado era questionado se mudaria de opinião com relação à marca escolhida, em caso positivo, perguntava-se a justificativa da mudança. Todas as entrevistas foram gravadas e posteriormente transcritas.

Após a degustação, o participante era convidado a responder um questionário semiestruturado com avaliação de 12 atributos ligados à inovação em sucos, conforme Quadro 3, composto por uma escala de 5 pontos. Os atributos foram escolhidos baseando-se na literatura acerca de atributos inovadores em sucos. $\mathrm{Na}$ sequência era questionado se o respondente considerava o suco escolhido inovador e, finalmente, foi feito o levantamento socioeconômico.

\section{Quadro 3 - Atributos avaliados no questionário}

\begin{tabular}{|c|c|c|}
\hline \multicolumn{2}{|c|}{$\begin{array}{l}\text { Atributos Inovadores em sucos } \\
\text { (KOTLER, 1999; RICHERS, 2000; GUO e YIN, 2014) }\end{array}$} & Atributos avaliados na pesquisa \\
\hline \multirow{8}{*}{$\begin{array}{l}\text { Aumento da } \\
\text { Qualidade do } \\
\text { Produto }\end{array}$} & Textura & Textura do Produto (espesso, ralo, etc) \\
\hline & Sabor & Sabor (paladar) \\
\hline & Aroma & Aroma (cheiro) \\
\hline & Criação de novos sabores & Criação de novos sabores \\
\hline & Conveniência (disponibilidade para aquisição) & Atributo não avaliado \\
\hline & Aparência & Atributo não avaliado \\
\hline & Branding & Atributo não avaliado \\
\hline & $\begin{array}{l}\text { Aspectos Nutricionais que priorizam a saúde } \\
\text { (integral, baixo nível de açúcar, sódio; } \\
\text { incremento de vitaminas, sais minerais, fibras, } \\
\text { etc) }\end{array}$ & $\begin{array}{l}\text { Redução da quantidade de calorias } \\
\text { Melhoria dos valores nutricionais (vitaminas, } \\
\text { sais minerais, fibras) }\end{array}$ \\
\hline \multirow{2}{*}{$\begin{array}{l}\text { Melhoria de } \\
\text { Propriedades } \\
\text { Úteis }\end{array}$} & $\begin{array}{l}\text { Propriedades Funcionais (baixo nível de } \\
\text { conservadores, estabilizadores, etc) }\end{array}$ & Redução de conservadores, estabilizadores \\
\hline & Conservação do produto & Atributo não avaliado \\
\hline \multirow{2}{*}{$\begin{array}{l}\text { Mudanças no } \\
\text { Design } \\
\text { (Embalagem) }\end{array}$} & Design atrativo (cores, formato, ergonomia) & $\begin{array}{l}\text { Design Gráfico da embalagem (cores, } \\
\text { elementos visuais, fonte utilizada) }\end{array}$ \\
\hline & Comunicação (textos de fácil acesso) & $\begin{array}{l}\text { Informações nutricionais acessíveis } \\
\text { Comunicação da embalagem (textos escritos) }\end{array}$ \\
\hline \multirow{3}{*}{$\begin{array}{l}\text { Redução de } \\
\text { Impactos } \\
\text { Ambientais }\end{array}$} & Embalagem Reciclável & $\begin{array}{l}\text { Material da embalagem (Plástico, vidro, tetra } \\
\text { pak) }\end{array}$ \\
\hline & Ausência de agrotóxicos (orgânico) & Atributo não avaliado \\
\hline & $\begin{array}{l}\text { Produção que prioriza a preservação do meio } \\
\text { ambiente }\end{array}$ & $\begin{array}{l}\text { A marca se preocupa com a redução dos } \\
\text { impactos ambientais }\end{array}$ \\
\hline
\end{tabular}

Fonte: Elaborado pelos autores.

Os dados coletados foram analisados qualitativamente, utilizando-se a técnica de análise de conteúdo clássica, que, conforme Bardin (2011), tem a finalidade de explorar as falas dos participantes. A técnica sugerida pode ser indicada para suportar análises que contemplem a necessidade de explicitação e 
sistematização de conteúdo das mensagens, sejam estas passíveis ou não de quantificação, utilizando deduções lógicas e justificadas originadas nas mensagens que estão sendo analisadas (BARDIN, 2011).

Para complementar a análise de conteúdo clássica, utilizou-se uma análise quantitativa de frequência das respostas registradas pelos respondentes, buscando clarificar melhor o processo decisório de baixo envolvimento. A seguir, apresenta-se a descrição e análise dos resultados encontrados.

\section{DESCRIÇÃO E ANÁLISE DOS RESULTADOS}

Em relação à primeira etapa, que foi a respeito do que os consumidores consideram como inovação em um suco, no geral os respondentes apresentaram dificuldade para sugerir algum atributo, por isso as ausências de respostas foram mais frequentes (18) do que aqueles que conseguiram sugerir algum atributo inovador espontaneamente (13). Dentre esses últimos, foram identificadas as seguintes características consideradas inovadoras: embalagem (6), ter menos conservantes (2), ter gominhos (2), gosto parecido com o da fruta (1) e sabores diferentes (1). Quatro respondentes declararam que não consideram inovação algo importante para sucos e dois traduziram o que acreditavam ser inovação em sucos citando a marca Del Valle (líder de mercado).

Antes da degustação dos produtos, as marcas escolhidas foram, por ordem de preferência: Del Valle, Natural One, Sufresh, e Do Bem. Após a degustação e solicitação de escolha dentre os quatro sucos, houve modificação nas decisões, Del Valle permanecendo em primeiro, seguida por Do Bem e Natural One (empatados) e Sufresh em último, como apresentado na Tabela 1.

Tabela 1 - Escolhas dos participantes antes e depois da degustação

\begin{tabular}{|c|c|c|c|c|c|}
\hline \multirow{2}{*}{ Grupos } & \multirow{2}{*}{ Marca Escolhida } & \multicolumn{4}{|c|}{ Degustação } \\
\hline & & Antes & & & \\
\hline \multirow{3}{*}{ I } & Del Valle & 19 & & 11 & \\
\hline & & & 23 & & 15 \\
\hline & Sufresh & 4 & & 4 & \\
\hline \multirow{4}{*}{ II } & Natural One & 6 & & 8 & \\
\hline & & & 8 & & 16 \\
\hline & Do Bem & 2 & & 8 & \\
\hline & Total & 31 & & & \\
\hline
\end{tabular}

Fonte: dados da pesquisa.

A questão seguinte da primeira etapa, sobre fatores considerados importantes no momento de se escolher um suco na gôndola, realizada antes da degustação, foram identificados sete atributos, sendo o mais citado o "Sabor", com 13 respostas, em seguida vieram marca com 9, embalagem com 8 e preço com 7 (Tabela 2). O respondente 17, por exemplo, afirmou ter escolhido o suco (Natural One) devido ao seu "sabor parecido com original, sem conservantes". Para ele, "menos conservantes é mais inovação". 
Tabela 2 - Atributos citados pelos respondentes para escolher sucos antes da degustação

\begin{tabular}{lcccc}
\hline \multirow{2}{*}{$\begin{array}{l}\text { Atributos de escolha citados pelos } \\
\text { respondentes }\end{array}$} & Grupo I & Grupo II & Total & $\%$ \\
\cline { 2 - 4 } & 8 & 5 & 13 & $30 \%$ \\
\hline Sabor & 8 & 1 & 9 & $20 \%$ \\
Marca & 5 & 3 & 8 & $18 \%$ \\
Embalagem & 7 & & 7 & $16 \%$ \\
Preço & 3 & 1 & 4 & $9 \%$ \\
Textura & 2 & 0 & 2 & $5 \%$ \\
Aspectos Nutricionais que priorizam a saúde & 0 & 1 & 1 & $2 \%$ \\
Propriedades Funcionais & $\quad$ Total & $\mathbf{1 1}$ & $\mathbf{4 4}$ & $\mathbf{1 0 0 , 0 0 \%}$ \\
\hline
\end{tabular}

Fonte: dados da pesquisa.

$\mathrm{Na}$ Tabela 3 encontram-se as médias dos escores dos atributos devidamente avaliados pelos respondentes. Cada item deveria receber uma avaliação, que deveria ir de 1 (discordo totalmente) a 5 (concordo totalmente). Todos os itens apresentaram média superior a 3, com destaque aos itens "Informações nutricionais acessíveis" $(4,33)$ e "Sabor" $(4,31)$, no grupo I, e no grupo II, "Redução de conservadores, estabilizadores, etc "e "Sabor" (ambos 4,53).

Tabela 3 - Escores de avaliações de atributos inovadores em sucos

\begin{tabular}{lcc}
\hline \multirow{2}{*}{ Atributos } & \multicolumn{2}{c}{ Média } \\
\cline { 2 - 3 } & Grupo I & Grupo II \\
\hline Sabor & 4,31 & 4,53 \\
Aroma & 3,86 & 3,86 \\
Textura & 3,92 & 4,33 \\
Criação de novos sabores & 3,61 & 3,94 \\
Redução dos impactos ambientais & 4,17 & 4,42 \\
Redução da quantidade de calorias & 3,59 & 3,49 \\
Melhoria dos valores nutricionais & 3,76 & 3,98 \\
Redução de conservadores, estabilizadores, etc & 4,28 & 4,53 \\
Informações nutricionais acessíveis & 4,33 & 3,94 \\
Material da embalagem & 3,30 & 4,03 \\
Design Gráfico da embalagem & 3,73 & 3,87 \\
Comunicação da embalagem & 3,44 & 4,07 \\
\hline Média & $\mathbf{3 , 8 6}$ & $\mathbf{4 , 0 8}$ \\
\hline Fonte: dados da pesquisa. & &
\end{tabular}

Fonte: dados da pesquisa. 
Após a degustação, foram identificadas 18 (58\%) alterações de decisões, das quais, 6 ocorreram dentro do mesmo grupo e 12 entre sucos de grupos diferentes. Apenas 2 dos 12 respondentes alteraram sua decisão inicial de um suco do Grupo II (Natural One), para um suco do Grupo I (Sufresh). As 10 outras alterações se deram de uma escolha inicial feita por um suco do Grupo I para outro do Grupo II. A Tabela 1 supracitada mostra as alterações nas decisões antes e após a degustação.

A amostra pesquisada evidenciou diversos fatores que relacionam a compra de sucos prontos a uma escolha de baixo envolvimento: (a) limitações relacionadas ao apontamento do que sejam atributos inovadores; (b) a rapidez na escolha do suco; (c) a declaração irreflexiva acerca de atributos como sabor, antes mesmo de uma degustação; e (d) o considerável índice de mudanças de escolha após a degustação (18 dos 31 respondentes mudaram de escolha após a degustação) sugerem que os consumidores jovens utilizam-se de heurísticas e crenças de mercado para realizar suas escolhas de sucos prontos.

A seguir, os resultados encontrados serão discutidos à luz da literatura relacionada às decisões de baixo envolvimento. Priorizou-se as ponderações acerca dos atributos apontados pelos respondentes como mais importantes na escolha de sucos prontos: marca, preço, sabor e embalagem.

\section{Heurística, crenças de mercado e inovação}

As limitações apresentadas pelos respondentes para apontar atributos inovadores em sucos evidencia as dificuldades para se identificar o que é inovação nesta categoria de produto. Mesmo consideradas incrementais (ROGERS; SHOEMAKER, 1971; ROGERS, 1983), as inovações são importantes para manter produtos em situação de vantagem competitiva diante de seus concorrentes. A intensa concorrência e crescimento apresentados no mercado de sucos prontos (ABIR, 2014; ABRAS, 2014) sugerem a importância de ações inovadoras.

A despeito dos esforços empreendidos pelas marcas analisadas, os entrevistados pouco tinham a declarar, por exemplo, acerca de atributos ligados à melhoria de propriedades úteis (apenas dois respondentes citaram como inovação o suco possuir menos conservantes) e nenhum dos entrevistados identificou como inovação algum aspecto de promovesse a redução de impactos ambientais, características importantes na inovação em sucos, conforme Pleschak e Sabisch (1996) apud Guo e Yin (2014).

A inovação foi percebida em poucos aspectos. Basicamente, o sabor (mais parecido com a fruta original), a embalagem (com facilidades de abertura, transparente e resistente) e a textura (com ou sem gominhos) foram apontadas como aspectos de inovação na pergunta inicial. A maioria dos respondentes $(58 \%)$ não conseguiu identificar atributos inovadores ou se o fato do produto ser inovador interferiria em suas escolhas.

Nenhum dos respondentes percebeu diferenças de inovação entre os Grupos I e II, nem mesmo diferenças na composição do suco, apesar do Grupo II ser composto por sucos integrais (100\% fruta). Eles também não citaram que a comunicação visual do suco Do Bem estava direcionada aos jovens. Poucos respondentes (2) valorizaram o fato de que os sucos do Grupo II declaravam não possuir conservadores, açúcar ou estabilizadores. 
A ausência de aprofundamento no conhecimento de informações disponíveis nas embalagens corrobora os achados de Tversky e Kahneman (1974), pois os respondentes mostraram pouco interesse em analisar os dados disponíveis, retendo-se à avaliação de alguns considerados mais relevantes (sabor, embalagem e textura).

De maneira incoerente com as decisões racionais, todos os respondentes deram notas acima de 3 (apontando concordância) para todos os atributos inovadores sugeridos na parte do questionário fechado, sendo que os respondentes que escolheram sucos do Grupo II apresentaram média de escores de 4,08, acima da média de escores do Grupo I, que foi 3,86 (vide Tabela 3). Todos os respondentes aparentam concordar que os atributos inovadores apontados por Pleschak e Sabisch (1996) apud Guo e Yin (2014) são importantes na inovação em sucos, apesar de não os terem identificado claramente na pergunta aberta inicial.

À luz do que propõe Hansen (2005), o consumo de sucos prontos precisa ser analisado como um fenômeno psicológico, que envolve experiências e aspectos situacionais. Por se tratar de um produto de escolha de baixo envolvimento, é possível que os consumidores considerem, no momento de decidir, heurísticas de natureza visual (RUSSO; LECLERC, 1994; CHANDON et al., 2009), observando o que é diferente dos demais. A embalagem transparente - Natural One - em contraposição às outras tradicionais, por exemplo, foi citada por alguns respondentes (3) como um diferencial.

O momento da degustação foi uma oportunidade para os respondentes envolverem-se mais racionalmente na escolha. Nesta ocasião, verificou-se que a tendência heurística para decisões e declarações rápidas, que foi percebida na pergunta inicial sobre o que seria uma inovação em sucos (os atributos inovadores citados na primeira pergunta somaram apenas 12 frequências) alterou-se consideravelmente. Após a degustação, os respondentes aumentaram seus apontamentos do que consideravam inovador para 35 frequências. $\mathrm{O}$ aumento nos argumentos de escolha dos respondentes concorda com Maheswaran et al. (1992), que demonstrou que os consumidores tendem a abandonar decisões heurísticas e decidirem-se de maneira mais consciente à medida que tomam conhecimento de informações sobre os atributos do produto.

\section{Heurística, crenças de mercado e marca}

Quando o participante, diante das quatro marcas, era convidado a escolher uma delas antes da degustação, observou-se uma resistência em buscar informações visuais e escritas. As escolhas, em sua maioria, eram rápidas e, aparentemente, irreflexivas. Mesmo quando foram convidados a analisar as caixinhas de forma atenciosa, podendo manipulá-las antes da escolha, a maioria dos respondentes dizia que já havia tomado sua decisão. Verificou-se que a observação visual das características da embalagem foi importante, pois era a característica em que a inovação era mais facilmente percebida.

O comportamento de pouco envolvimento evidenciado pelos respondentes parece corroborar as escolhas iniciais feitas por eles. Antes da degustação, 19 participantes $(61 \%)$ escolheram a marca líder de mercado - Del Valle. A razão desta escolha foi, de acordo com os depoimentos coletados, principalmente devido ao conhecimento da marca, da tradição e do preço. Esse resultado condiz com Maheswaran et al. (1992), os quais sugerem que a marca é um importante item na formação da heurística. Em situações de baixo envolvimento, ainda segundo os autores, os consumidores tendem a escolher pela marca mais conhecida. 
A influência da marca líder em decisões de baixo envolvimento pôde ser observada na frequência com que os respondentes apontaram o atributo marca (8) para escolher o suco antes da degustação (vide Tabela 2). Ao observar-se que os respondentes do Grupo I apontam também atributos importantes como sabor (8) e textura (3) antes mesmo da degustação, é possível que estejam remetendo-se às suas experiências anteriores com sucos prontos, reforçando a evidência da decisão pela marca. Esse comportamento relaciona-se às crenças de mercado ligadas à marca, tais como "compre a melhor e mais conhecida marca" (HOYER; BROWN, 1990 apud LEONG, 1993), ou "firmas que fazem mais propagandas vendem os melhores produtos" (DUNCAN; OLSHAVSKY, 1982; DUNCAN, 1990).

Outra questão importante a ser discutida é o aspecto do sabor: é possível que o Grupo II tenha aumentado o número de escolhas por ter sucos integrais, enquanto o que mais perdeu adeptos foi o Grupo I, caracterizado pelo néctar (polpa de laranja adicionada a açúcares e água). O atributo 'marca', tão importante para escolha do suco antes da degustação, mostrou-se menos relevante que o sabor após a experimentação. Esses resultados sugerem que o aumento do envolvimento, devido à degustação, conforme propõem Maheswaran et al. (1992) e Babutsidze (2012), levou os respondentes a abrir mão de heurísticas de rápida decisão em direção à marca, conduzindo-os a uma decisão mais racional, baseada em uma nova experiência com atributos ainda não considerados racionalmente nas decisões.

\section{Heurística, crenças de mercado e preço}

A princípio, o preço do suco foi considerado um fator importante para fundamentar a escolha (vide Tabela 2). Porém, após a degustação, mesmo dentre alguns participantes que inicialmente haviam escolhido o produto baseando-se no preço mais baixo, afirmaram que escolheriam outra marca mais cara devido ao sabor.

Já o atributo sabor manteve-se como um critério importante nos dois grupos, apresentando-se estável no Grupo I e aumentando no Grupo II à medida que o envolvimento com os sucos se elevou (convite à degustação). No grupo dos 10 respondentes que alteraram sua decisão após a degustação evidencia-se o decréscimo da importância dos atributos marca e preço e o crescimento do atributo sabor após a degustação (Tabela 4).

Tabela 4 - Atributos importantes para o grupo de respondentes que alteraram sua decisão de compra

\begin{tabular}{|c|c|c|}
\hline Atributos & Antes da degustação & Depois da Degustação \\
\hline Marca & 6 & - \\
\hline Preço & 5 & - \\
\hline Sabor & - & 8 \\
\hline Embalagem & 2 & 1 \\
\hline Textura & - & 1 \\
\hline Aspectos Nutricionais que priorizam a saúde & - & 1 \\
\hline Total & 13 & 11 \\
\hline
\end{tabular}

Fonte: dados da pesquisa. 
Esse comportamento pode ser compreendido quando se considera crenças de mercado relacionadas à marca e ao preço. Quando decidiram de forma heurística com baixo envolvimento, os respondentes tenderam a usar o preço como perspectiva de escolha, ou seja, como parâmetro de qualidade entre diferentes alternativas pouco familiares (SCIOTVSKY, 1945 apud DUNCAN,1990; WOLINSKY, 1983), no caso, sucos do grupo II. Desta forma, combinando crenças de mercado (DUNCAN, 1990) e relacionando preço com qualidade do produto (ENIS; STAFFORD, 1969; GARDNER, 1970; MONROE, 1976; OLSON, 1977), muitos respondentes tenderam a escolher marcas líderes que ofereciam a melhor relação custo/benefício, comportando-se conforme a crença de mercado "compre a melhor e mais conhecida marca" (HOYER; BROWN, 1990 apud LEONG, 1993).

\section{CONSIDERAÇÕES FINAIS}

O objetivo da presente pesquisa foi verificar a influência da heurística e crenças de mercado nas escolhas consumeristas de consumidores em produtos de baixo envolvimento e que apresentam inovações. A pesquisa identificou que os principais atributos apontados pela amostra foram: sabor, marca, embalagem e preço.

Uma reflexão levantada com a análise dos dados é o impacto das heurísticas antes e depois do aumento de envolvimento com o produto, que ocorreu com a degustação. A experiência dos produtos permitiu uma escolha de forma mais racional. O estudo aponta que, no caso dos produtos de baixo envolvimento, os atalhos mentais proporcionados pela heurística são mais impactantes antes de experimentá-los.

As influências da heurística e das crenças de mercado na escolha dos sucos foram percebidas principalmente antes da degustação, quando os jovens pesquisados consideraram crenças de mercado como "compre a melhor e mais conhecida marca" e tenderam a utilizar a heurística para ignorar as informações disponíveis e decidirem de maneira rápida e pouco reflexiva.

Eles parecem menos importantes para a decisão quando se experimenta os produtos antes da escolha. Não é possível supor, contudo, como ocorreria essa escolha algum tempo após as degustações. Assim, nas compras seguintes, o consumidor voltaria a utilizar a heurística para decidir a respeito do suco ou utilizaria formas mais racionais para embasar sua decisão? Outro estudo poderia responder a esse questionamento.

A inovação precisa ser percebida pelo consumidor para se tornar um diferencial real. Esta pesquisa pode ser um ponto de partida para novas investigações ligadas ao tema, como estudos relacionados à efetividade de estratégias para alcançar novos consumidores através de maior envolvimento com seus produtos, que podem ajudar a compreender como o consumidor realiza suas decisões de compra. Também se constatou que diante de uma variedade de produtos e marcas diferentes, a heurística pode ocupar importante papel em todo o processo de decisão e na percepção de inovações em produtos de baixo envolvimento, tendo implicações para a pesquisa acadêmica e para o ambiente gerencial.

Do ponto de vista acadêmico, a percepção da inovação, alicerçada por construções teóricas baseadas nos pressupostos da heurística, pode trazer uma nova perspectiva para o entendimento do comportamento do consumidor e precisa ser considerada em modelos teóricos aplicados ao consumo de produtos de baixo envolvimento. Em termos gerenciais, a presente pesquisa pode colaborar com o planejamento e 
implementação de estratégias de produtos de baixo envolvimento, com vistas ao alcance e manutenção de novas fatias de mercado, no qual é preciso considerar a heurística nas escolhas dos consumidores e a possibilidade de diminuição de sua influência à medida que o consumidor tem contato mais atencioso com o produto em questão.

O estudo, devido ao caráter exploratório e amostragem por conveniência, está limitado ao seu contexto de pesquisa e não pode ser generalizado. Sugere-se novas pesquisas com amostragem ampliada e quantitativos na área, com vistas ao aprofundamento da discussão proposta neste trabalho.

\section{REFERÊNCIAS}

ABIR. Associação Brasileira das Indústrias de Refrigerantes e Bebidas Não Alcoólicas. Disponível em: <http://abir.org.br/>. Acesso em: 13 Dez. 2014.

ABRAS. Associação Brasileira de Supermercados. SUPERHIPER. Revista Ano 40, n. 453, Março, 2014. Disponível em: <www.abras.com.br>. Acesso em: 12 Dez. 2014.

ABREU, Gustavo Melione. Posicionamento de marca no mercado de sucos e néctares: uma análise do caso "do bem". Revista Augustus, v. 18, n. 35, p. 74-89, 2013

ALLISON, R; K. UHL, Influence of Beer Brand Identification on Taste Perception, Journal of Marketing Research, v.1, August, 1964. pp. 36-39

BABUTSIDZE, Z. How do consumers make choices? A survey of evidence. Journal of Economic Surveys, v. 26, n. 4, pp. 752-762, 2012.

BARDIN, L. Análise de conteúdo. São Paulo: Edições 70, 2011.

BEALES, H., MAZIS, M. B., SALOP, S. C., \& STAELIN, R. Consumer Search and Public Policy, Journal of Consumer Research, v.8 (June), 11-22. 1981.

BRESSAN, C. Divergências no Comportamento Decisório de Franceses e Brasileiros Frente a uma Decisão Estratégica de Sistemas de Informação. 338 p. Tese (Doutorado em Administração) - EAESP/FGV, 2004.

BEZERRA, J. M. F.; LEONE, R. J. G.. Efeito ancoragem e relações de consumo: um estudo com produtos da cesta básica. Revista Ambiente Contábil, v. 5, n. 2, p. 68, 2013. CIARELLI, Gustavo; CIARELLI, G.; AVILA, M. A influência da mídia e da heurística da disponibilidade na percepção da realidade: um estudo experimental. Revista de Administração Pública, v. 43, n. 3, p. 541-562, 2009.

CITRUS BR. Associação Nacional dos Exportadores de Sucos Cítricos. Disponível em : < http://www.citrusbr.com/\#>. Acesso em: 09 Dez 2014.

CHANDON, P., HUTCHINSON, J. W., BRADLOW, E. T., YOUNG, S. H. Does in-store marketing work? Effects of the number and position of shelf facings on brand attention and evaluation at the point of purchase. Journal of Marketing, $v$. 73, n. 6, pp. 1-17, 2009.

COSTA, D. D. M., BARBOSA, F. V., \& SILVA, C. H. P. D. Empreendedorismo e Inovação: O papel da Educação Superior nas Economias Mundiais. XI Colóquio Internacional sobre Gestão Universitária na América do Sul. Florianópolis, 2011.

DE PAULA, V. A. F. A estratégia de marcas próprias no varejo: concepção gestão de marcas próprias na Inglaterra e no Brasil. 130 f. Tese (Doutorado em Engenharia de Produção) - Departamento de Engenharia de Produção, Universidade Federal de São Carlos, São Carlos. 2008.

DIJKSTERHUIS, A.; SMITH, P. K.; BAAREN, Rick B. V..; WIGBOLDUS, D. H. J. The unconscious consumer: Effects of environment on consumer behavior. Journal of Consumer Psychology, v.15, n.3, pp.193-202, 2005.

DUNCAN, C. P., R. W. OLSHAVSKY. External Search: The Role of Consumer Beliefs, Journal of Marketing Research, v.19, February, p. 32-43, 1982.

DUNCAN, C. P. Consumer Market Beliefs: a Review of the Literature and an Agenda For Future Research. In: GOLDBERG, Marvin E.; GORN, Gerald; POLLAY, Richard W. (ed). NA - Advances in Consumer Research, v.17, Provo, UT: Association for Consumer Research, p. 729-736, 1990.

ENIS, B. M. ; STAFFORD, J. E., Consumers' Perceptions of Product as a Function of Various Informational Inputs, in Marketing Involvement in Society and the Economy, ed. P. R. McDonald, Chicago: American Marketing Association, 1969.

GARDNER, D. An Experimental Investigation of the Price-Quality Relationship, Journal of Retailing, 46 (Fall), 3940. 1970. 


\section{ENVOLVIMENTO}

GARDNER, D. Is There a Generalized Price-Quality Relationship?, Journal of Marketing Research, 8 (May), 24143. 1971.

GOMES, D. T., MAIA MUNIZ, R., TEIXEIRA DIAS, A., GONÇALVES, C. A. Apresentação do processo de formação da estratégia: um estudo de caso em empresa inovadora. Revista de Administração da UFSM, v. 5, n. 3, p. 413-438, 2012.

GUO, X; YIN, W. Consumers' Purchasing Behavior - The impact of product innovation. 69 f. Master Thesis (MS in Globalization, Brands and Consumption 2013/2014). Department of Business and Administration, Lund University. Sweden. 2014.

JACOBY, J.; SZYBILLO G.; BUSATO-SCHACH J. Information Acquisition Behavior in Brand Choice SITUATIONS. JOURNAL OF CONSUMER RESEARCH, V.3, P. 209-216, MARCH, 1977.

JOHN, D. R., SCOTT, C. A., \& BETTMAN, J. R. Sampling Data for Covariation Assessment: The Effect of Prior Beliefs on Search Patterns. Journal of Consumer Research, v.13, p. 38-47June, 1986.

HANSEN, T. Understanding consumer perception of food quality: the cases of shrimps and cheese. British Food Journal. v. 107 , Iss 7, p. 500-525, 2005.

KAHNEMAN, D.; TVERSKY, A.. On the psychology of prediction. Psychological review, v. 80, n. 4 . 237,1973.

LEONG, S. M. Consumer decision making for common, repeat-purchase products: a dual replication. Journal of Consumer Psychology, v. 2, n. 2, p.193-208, 1993.

LIMA FILHO, R. N., BRUNI, A. L., SAMPAIO, M. S., CORDEIRO FILHO, J. B. C., \& CARVALHO JÚNIOR, C. V. D. O Heurísticas e Práticas Orçamentárias: um estudo experimental. Sociedade, Contabilidade e Gestão, v. 5, n. 1, p.42-58, 2010.

LINDENBERG, S. The method of decreasing abstraction. In: COLEMAN, James S.; FARARO, Thomas J. (ed.). Rational choice theory. New York: Sage, p. 3-20,1992.

LUPPE, M. R.; ANGELO, C. F. As decisões de consumo e a heurística da ancoragem: uma análise da racionalidade do processo de escolha. Rev. Adm. Mackenzie, v. 11, n. 6, p.81-106, Nov./Dez, 2010.

DA SILVA MACEDO, M. A., DANTAS, M; M., DE OLIVEIRA, R. F. S.. Análise do Comportamento Decisório de Profissionais de Contabilidade sob a perspectiva da Racionalidade Limitada: Um Estudo sobre os Impactos da Teoria dos Prospectos e das Heurísticas de Julgamento. Revista Ambiente Contábil, p. 1-16, v. 4, n. 1, 2012.

MALHOTRA, N. K. Pesquisa de marketing: uma orientação aplicada. 3. ed. Porto Alegre: Bookman, 2001. MALHOTRA, N. K. Pesquisa de marketing: uma orientação aplicada. 4.ed. Porto Alegre: Bookman, 2006.

MAHESWARAN, D.; MACKIE, D. M.; CHAIKEN, S.. Brand name as a heuristic cue: The effects of task importance and expectancy confirmation on consumer judgments. Journal of Consumer Psychology, p, 317-336, v, 1, n. 4, 1992.

MARCH, J, G. A Primer on Decision Making - How Decisions Happen. New York: The Free Press, 289 p, 1994.

NELSON, P.. Information and Consumer Behavior. Journal of Political Economy, v. 78, n.2, p. 311-329, 1970.

PAYNE, John W. Heuristic Search Processes in Decision Making. In: ANDERSON, Beverlee B. (ed). NA - Advances in Consumer Research, v.3, Cincinnati, OH: Association for Consumer Research, p. 321-327, 1976.

RICHERS, R. Marketing: uma visão brasileira. $3^{a}$ edição. São Paulo: Negócio Editora, 2000.

ROGERS, Everett. M. Diffusion of innovations. New York, 1983.

ROGERS, E. M., SHOEMAKER, F. F. Communication of innovations. New York: Free Press, 1971.

RUSSO, J. E.; SCHOEMAKER, P. J. H. Decision Traps - The Ten Barriers to Brilliant Decision-Making and How to Overcome Them. New York: Fireside, 1990.

RUSSO, J. E.; LECLERC, F.. An eye-fixation analysis of choice processes for consumer nondurables. Journal of Consumer Research, v.21, . pp. 274-290,1994

SALOP, S. Parables of Information Transmission in Markets -The Effect of Information on Consumer Market Behavior, In: MITCHELL, A. Chicago: American Marketing Association, p.3-12, 1979.

SANTOS, M. J. M. D., SPERS, E. E., PONCHIO,, M. C., ROCHA, T. V. Heurísticas no consumo de serviços de educação superior. Revista Brasileira de Marketing, v. 9, n. 1, p. 40-63, 2010.

SCITOVSKY, T. Some Consequences of the Habit of Judging Quality By Price. The Review of Economic Studies, v.12, n. 32, p.100-105, 1945.

SHERMAN, S. J., CORTY, E. Cognitive Heuristics, in Handbook of Social Cognition, Vol. 1, eds. R. S. Wyler and T. K. Srull. Hillsdale, N. J.: Lawrence Erlbaum. 1984.

TONETTO, L. M., KALIL, L. L., MELO, W. V., SCHNEIDER, D. D. G., \& STEIN, L. M. O papel das heurísticas no julgamento e na tomada de decisão sob incerteza. Estudos de Psicologia. (Campinas), v. 23, n. 2, pp. 181-189, 2006. 
TRIVIÑOS, A. N. S.. Introdução à Pesquisa em Ciências Sociais: a pesquisa qualitativa em educação. São Paulo, Atlas, 1987.

TVERSKY, A.; KAHNEMAN, D.. Belief in the law of small numbers. Psychological bulletin, v. 76, n. 2, p. 105-110.1971. TVERSKY, A.; KAHNEMAN, D. Judgment under uncertainty: heuristics and biases. Science, New York, v. 185, n. 4157, p. 1124-1131, 1974.

VAN DE VEN, A.H.; POLLEY, D.E.; GARUD, R.; VENKATARAMAN, S. The Innovation Journey. New York: Oxford University Press, 1999.

WOLINSKY, A. Prices as Signals of Product Quality. Review of Economic Studies, p.647-658, 1983. 